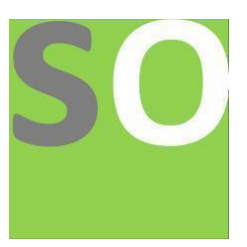

Article title: Assembly of Neuroscience to the model of mind

Authors: Pathma Liyanage[1]

Affiliations: School of Advanced Education, Research and Accreditation SAERA[1]

Orcid ids: 0000-0002-7045-4548[1]

Contact e-mail: pathma@boc.lk

License information: This work has been published open access under Creative Commons Attribution License http://creativecommons.org/licenses/by/4.0/, which permits unrestricted use, distribution, and reproduction in any medium, provided the original work is properly cited. Conditions, terms of use and publishing policy can be found at https://www.scienceopen.com/.

Preprint statement: This article is a preprint and has not been peer-reviewed, under consideration and submitted to ScienceOpen Preprints for open peer review.

DOI: 10.14293/S2199-1006.1.SOR-.PP2KE4Y.v1

Preprint first posted online: 05 January 2022

Keywords: mind models, cognitive science, neuroscience, psychology, cognitive architecture, cognitive models, brain models, cognition, organism, brain areas 


\section{ASSEMBLY OF NEUROSCIENCE TO THE MODEL OF MIND}

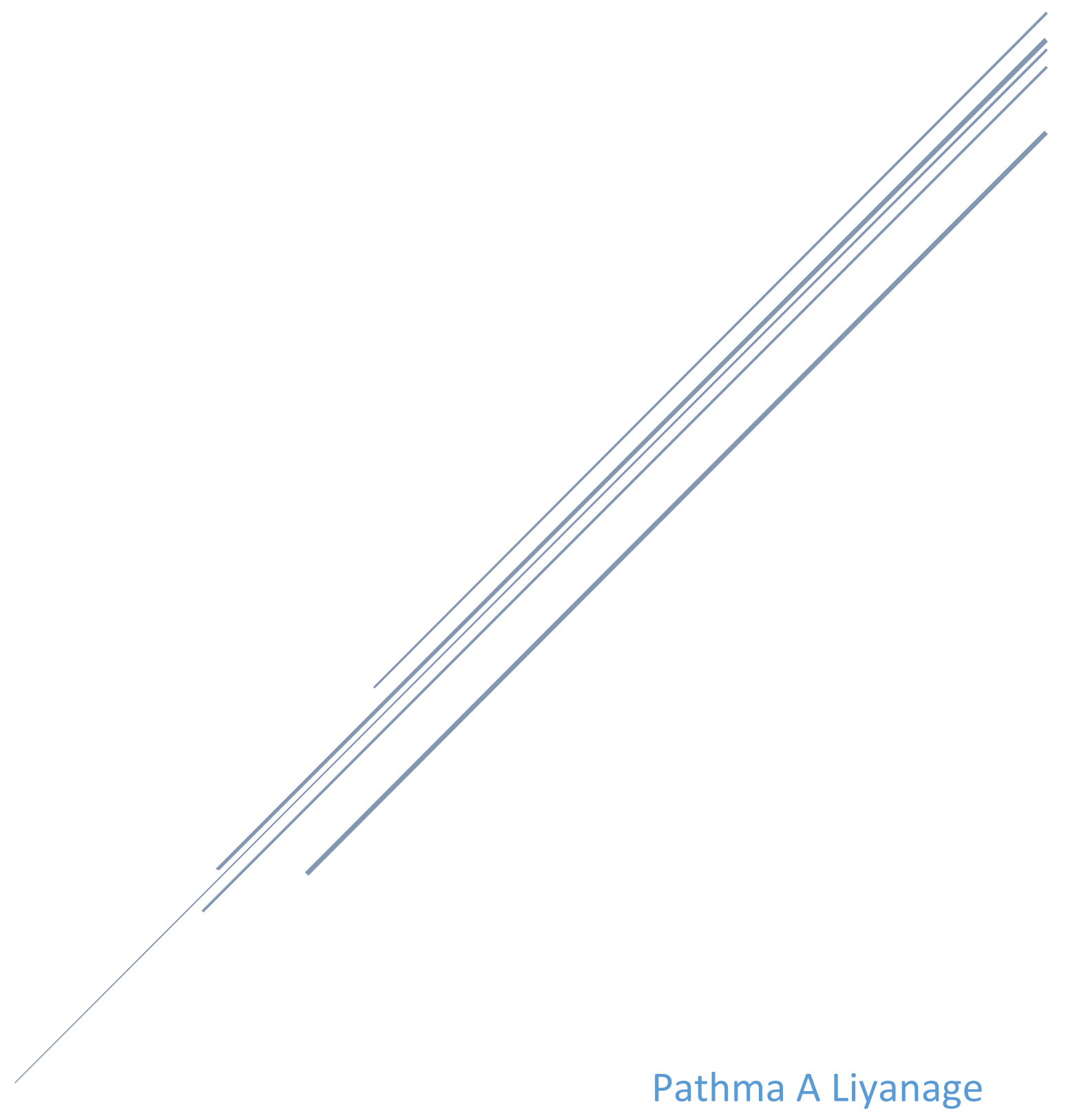




\begin{abstract}
Currently, there are several mind models developed as cognitive architectures and their main focus is to explain mind functions. However, few architectures explain the neural basis of the mind. Also, neuroscience explains the neural basis of the brain and is directly related to the mind. The study objective was to identify a mind model with a neural basis established in the model. Therefore, the study uses a systematic review of existing literature to find a mental model with a neural basis.

There are 300 articles identified in searching databases of PUBMED and Google Scholar. After duplicated removal, initial screening was done using an independent reviewer and remaining full-text articles were submitted to eligibility assessment. From the assessed fulltext articles, 9 full-text articles were selected for synthesis. From those selected architectures, considering the richness of mental functions and richness of neurological assemblies, features of the architectures op of ACT-R (Adaptive control of thoughts Rational) cognitive architecture, Leabra cognitive architecture and an embodied cognitiveaffective architecture select for inclusion in the final model.

The central structure of the mind is the amygdala. It gets sensory inputs through the sensory cortex and external stimuli through the thalamus. It processes those inputs using working memory as mPFC and dLPFC. After processing, the amygdala provides output as behavior. Also, brain structures of the partial cortex, cortex, para hippo cortex, perirhinal cortex, entorhinal cortex, subiculum, dentate gyrus, CA1 and CA3 areas of the hippocampus are used for memory encoding, memory retrieval, and critical learning. Overall, the posterior cortex processes the sensory and semantic information. The hippocampus works as episodic memory. The frontal cortex works as active maintenance of the thinking process. The basal ganglia works as action selection and the main part of the thinking process. This reveals the mind model with neurological circuit assemblies to it. The final model will limit to features of the currently existing literature.
\end{abstract}


1. Introduction to the Mind model

The consciousness, mental functions, events, properties, nature of mind, and their relationship to the physical body explains the philosophy of mind. Understanding the scientific, philosophical, and psychological view of the mind-brain system is the most complex and challenging subject.

According to the Sigmund Freud topographical model of the mind, there are at least 3 levels of mind, namely the conscious mind, the subconscious mind, and the unconscious mind. He explained it using an analogy of an iceberg as follows.

The conscious mind represents what we see in the iceberg, it explains a small amount of mental activity that we know of. The subconscious mind represents what we see in the iceberg on water level, it explains things that we could be aware of if we wanted to try. The unconscious mind represents a big amount of iceberg that we cannot see, it explains things we are unaware of and cannot become aware of.

According to him, the tip of the iceberg represents the conscious mind that has mental activities that we know of. The subconscious mind consists of all which can be recalled by memory. However, the most significant region is the unconscious mind. It includes many memories and thoughts that we are not aware of (Strangor et al., 2014).

The structure of a cognitive architecture explains component organization using information and processing, and how information flows between components.

The standard model of mind explains that the mind has distinct functionalities and is built of independent modules, and is not an undifferentiated pool of information and processing (Laird et al., 2017). It explains that cognitive architecture should consist of working memory, procedural long-term memory, declarative long-term memory, perception and motor control.

The scientific study of the nervous system is called neuroscience. It understands the fundamental and emergent properties of neurons and neural circuits by combining physiology, anatomy, molecular biology, developmental biology, cytology, mathematical modeling, and psychology. Therefore, the model of the mind is directly related to neuroscience. Each function of a mind has a certain neural circuit. This explains the physical basics of the mind. Cognitive science studies the mental functions of perception, 
attention, working memory, long-term memory, producing and understanding language, learning, reasoning, problem-solving, and decision making. Some mental models have developed as cognitive architectures and need to study those architectures to get a broad view of a mental model.

The Theory of Mind (ToM) has explained the idea that the meta representation ability of mental states in a specific neural circuitry depends on a domain-specific cognitive subsystem: a Theory of Mind Module (Gerrans and Stone 2008). In simple terms, the ToM is the ability to understand the difference of mental status from oneself to others (Zeng et al., 2020).

It explains domain specific input systems as gaze processing, voice processing, emotion recognition, goal detection, visual spatial processing, motor representations and procedural representations. Then those inputs pass to higher order amodal process, which includes working memory, recursion, secondary representations/collation, executive function, meta representation and language module. Then it passes to explanatory inference of mental state inferences.

Mind models are providing answers for the number of questions which are related to our mind. The way we think, the way people understand knowledge, and the way we anticipate the world and make decisions are represented by mind models.

According to Johnson-Laird (2004), perception and linguistic comprehension yield mind models. He also explained that thinking and reasoning are the internal manipulations of mental models. In other words, mind models are representations in the mind of real or imaginary situations (Laird et al., 2004). Extensive studies of mental models are carried out, since the models are important to understand the knowledge involved and would be able to stimulate and test it.

Some theorists and psychologists explored their knowledge to prove the existence of mind models while other suggested refinement in the existing mental model theory. (Gentner and Stevens, 2014).

According to the model theory, everyday reasoning depends on the simulation of events in mind models. It depends on simple primary assumptions as follows, (Laird et al., 2006). 
- $\quad$ Each model represents a possibility

- $\quad$ Models explain deduction, induction, and explanation

- $\quad$ Mind models represent only what is true

- $\quad$ Models are explained as iconic as far as possible

- $\quad$ Procedures for reasoning in mental models rely on counterexamples.

Young (1983) suggested eight tentative types of mind models namely strong analogy, surrogate, mapping, coherence, vocabulary, problem space, psychological grammar, and commonality (Young et al., 1983).

However Young does not mention the origin of the model types and their evaluation criteria. Later Laird (1989) cautions that all model distinctions may be artificial for they may represent the same reality (Laird et al., 1989).

Cognitive scientists may argue that the mental models are constructed as a result of perception (becoming aware of something by seeing), imagination (forming new ideas), knowledge, and the hearing or action of understanding something by using other senses by written or spoken communication (comprehension). Within the research, field scientists have identified several problems challenges, and confusions related to the construction of mental models.

Norman reports concluded that the mental models are fragmentary and worse (Norman et al., 1983).

1. Mental models are incomplete

2. Ability of people to run their models are severely limited

3. Models are unstable

4. Mind models do not have firm boundaries.

5. Mind models are unscientific

6. Mind models are parsimonious often.

7. People do extra physical operations rather than mind planning.

Due to the dynamic nature of mental models, they seem to be more process than outcome basis. Although mind model research had begun 3-4 decades ago, several issues remain to be solved. More work is to be done even for the clarification of definitions. 
It is better to do studies on what learning concepts help to explain the mind models phenomena. Also, researches should be carried out to find the answers to whether mind models are transitory or more permanent, how does mind models research relate to the current thinking in brain psychology. 


\section{Objectives}

In neuroscience studies, the nervous system explains the physical or biological view of the mind. Cognitive science studies mental functions and explains the logical view of the mind. To get a clear picture of a mental model, both the physical/neurological view and the logical/cognitive view are needed. A cognitive architecture should consist of biological structures assembled to explain insights from what is known from the brain science of humans. Such architectures should model using processes of cognitive neuroscience. Also, the model of mind is expected to contribute from biologically inspired cognitive architectures. This proposes that the mind model dynamically and cyclically form such a network according to neuroscience. Therefore, cognitive architecture should be biologically inspired to implement conceptually and computationally.

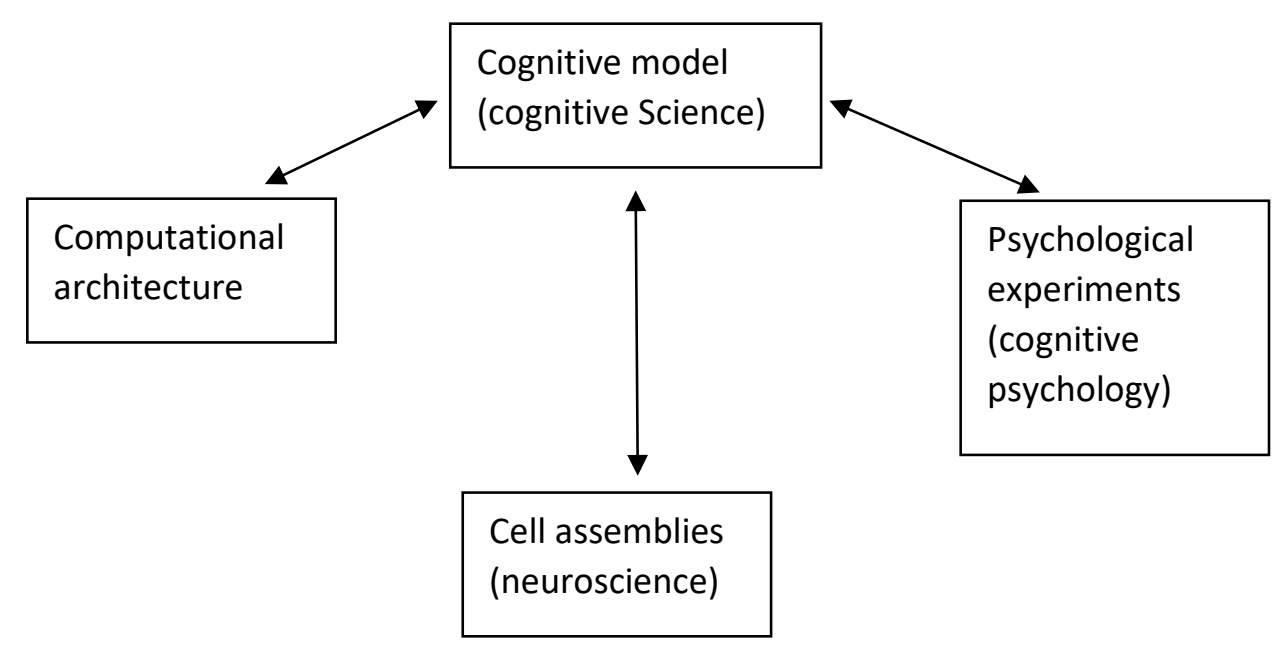

This revealed how is the grounding of the model of mind in neuroscience to be accomplished. Therefore, this study aims to develop a mental model with mental function as well as neural circuits. It can be explained as a neurologically inspired cognitive model of a mind.

The study uses a systematic review of literature developed in mind models, cognitive architectures, and neurological models and combines those to get a clear picture of the mind. 
3. Materials and methods

\subsection{Protocol and registration}

The method used to develop a neurologically inspired mind model was a systematic review. This systematic review uses literature related to mental models, cognitive architectures, and neuroscience models that will make assembly of neuroscience to the model of the mind.

The protocol used for a systematic review is PRISMA-P. This systematic review is for developing a mental model using literature, and not for health-related studies. Therefore, no need to register in the PROSPERO registry.

\subsection{Eligibility criteria}

Previous literature about cognitive science, mind models, fundamentals of neuroscience, developmental neuroscience, visual and auditory neuroscience was considered for the study. There is no year restriction, but only English language literature is considered for the study.

\subsection{Information sources}

Published research articles about cognitive science, mind models, fundamentals of neuroscience, developmental neuroscience, visual and auditory neuroscience used as information sources and those available in Google Scholar and PUBMED databases.

\subsection{Search}

Literature explained the model of mind used in this study. Search terms included are as follows: "cognitive architectures", "mental models", "fundamental of neuroscience", “developmental neuroscience", "visual and auditory neuroscience", "biologically inspired cognitive architectures". 


\subsection{Study selection}

According to the search criteria, information databases were searched and initial literature was identified. After identification of initial literature, duplicates were removed. Then record screening was done by an independent reviewer (Dr. Dayangi Hemalika). This record screening was done to confirm the inclusion criteria were met in the duplicate removed literature. The literature identified by both reviewers was selected for continuation. Afterward, full-text articles were assessed for eligibility using eligibility criteria. Then $\mathrm{n}$ articles were selected for qualitative synthesis. From the systematic reviewing of literature of mental models, the best model or combination of models was selected for further analysis.

\subsection{Data collection process}

When the search strings were applied to all databases, the result articles were downloaded. The results were imported for duplicate removal. Duplicate removed articles submitted to a screening process by two independent reviewers. Then, articles were assessed according to the eligibility criteria. Selected articles from assessing eligibility criteria were submitted to qualitative synthesis.

\subsection{Data items}

Each functional category of the selected mind model is considered a data item. Also, the neurological path identified by the systematic review was a data item. Motivations, major assumptions, relationships to neurobiology, modules, working memory, long-term memory, goals, learning, standard cognitive cycle, and model creation were extracted from each article (Schierwagen, 2010). 


\subsection{Risk of bias in individual studies}

The data was critically appraised by an independent reviewer. The record was appraised by the independent reviewer (Dr. Dayangi Hemalika) for inclusion criteria, which were met in the duplicate removed literature. This was done at the outcome level. The articles identified by both reviewers were selected for continuation.

\subsection{Summary measures}

There are 290 articles identified in searching databases of PUBMED and Google Scholar. Also, an additional record of 10 articles was identified in other sources of books. Then those identified 300 articles were submitted to duplicate removal. After duplicated removal, 200 articles were identified as unique articles. Afterwards, an initial screening was done by the independent reviewer. From the screened articles, 85 articles were excluded, and the remaining 115 full-text articles were submitted to eligibility assessment. Articles about cognitive science, mind models, fundamentals of neuroscience, developmental neuroscience, visual and auditory neuroscience were considered as the eligible articles for the study. There is no year's restriction, but only English language articles are considered for eligibility.

From assessed full-text articles, 9 full-text articles were selected for synthesis. Those selected articles described cognitive architectures of mental models and neurological paths related to cognitive functions. 


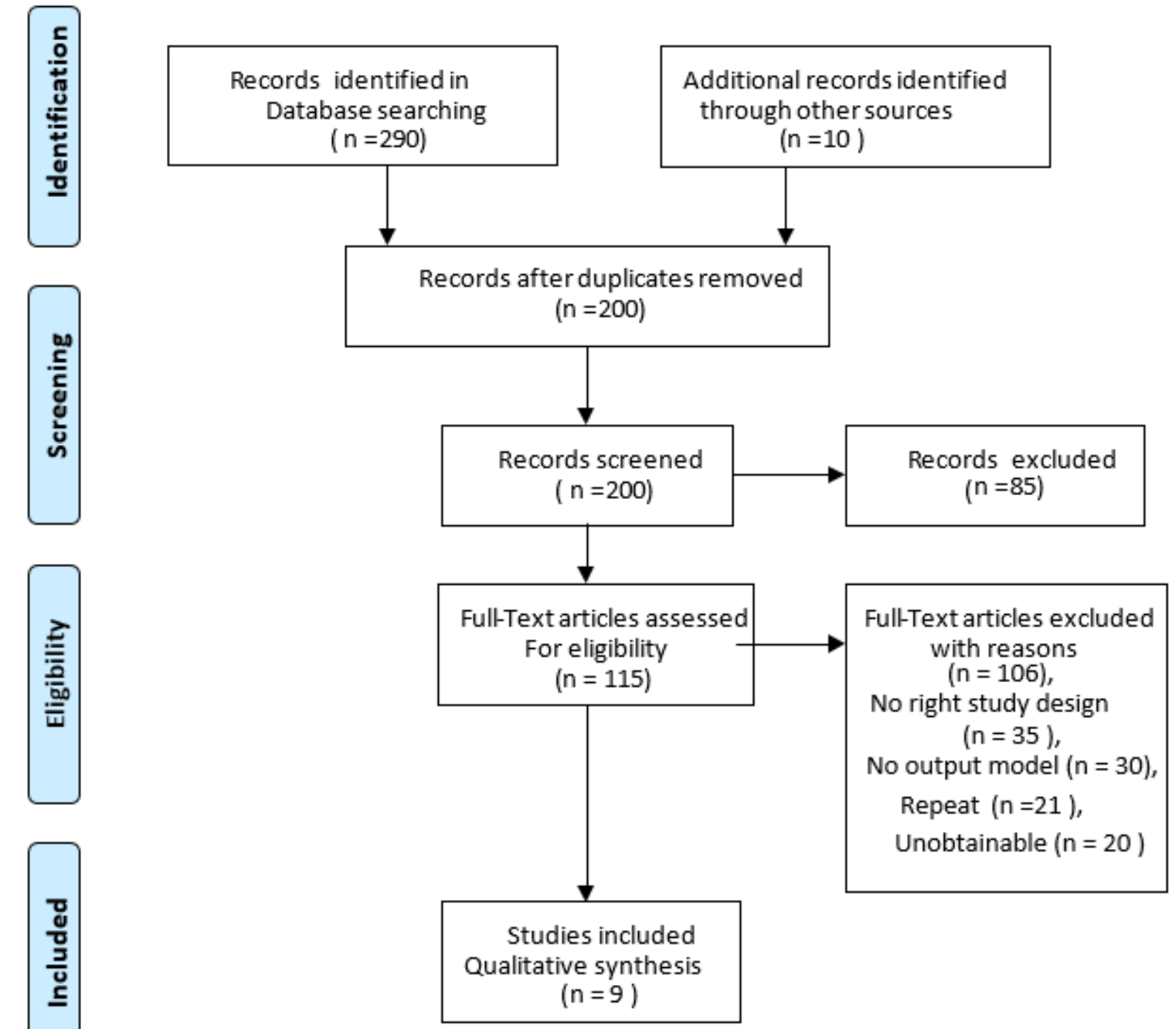

Figure 1: PRISMA diagram

\subsection{Synthesis of results}

A cognitive architecture should be biological structures assembled to explain insights from what is known from the brain science of humans. Such architectures should model using processes of cognitive neuroscience. Also, the model of mind is expected to contribute from biologically inspired cognitive architectures. This proposes that the mind model 
dynamically and cyclically forms such a network according to neuroscience. Therefore, cognitive architecture should be biologically inspired to implement conceptually and computationally.

Each function of the selected mind model will combine neurological path in articles of fundamental of neuroscience, developmental neuroscience and visual and auditory neuroscience for assembling the selected mind model to neuroscience.

This included a functional analysis and a structural analysis of the mind (Schierwagen, 2010).

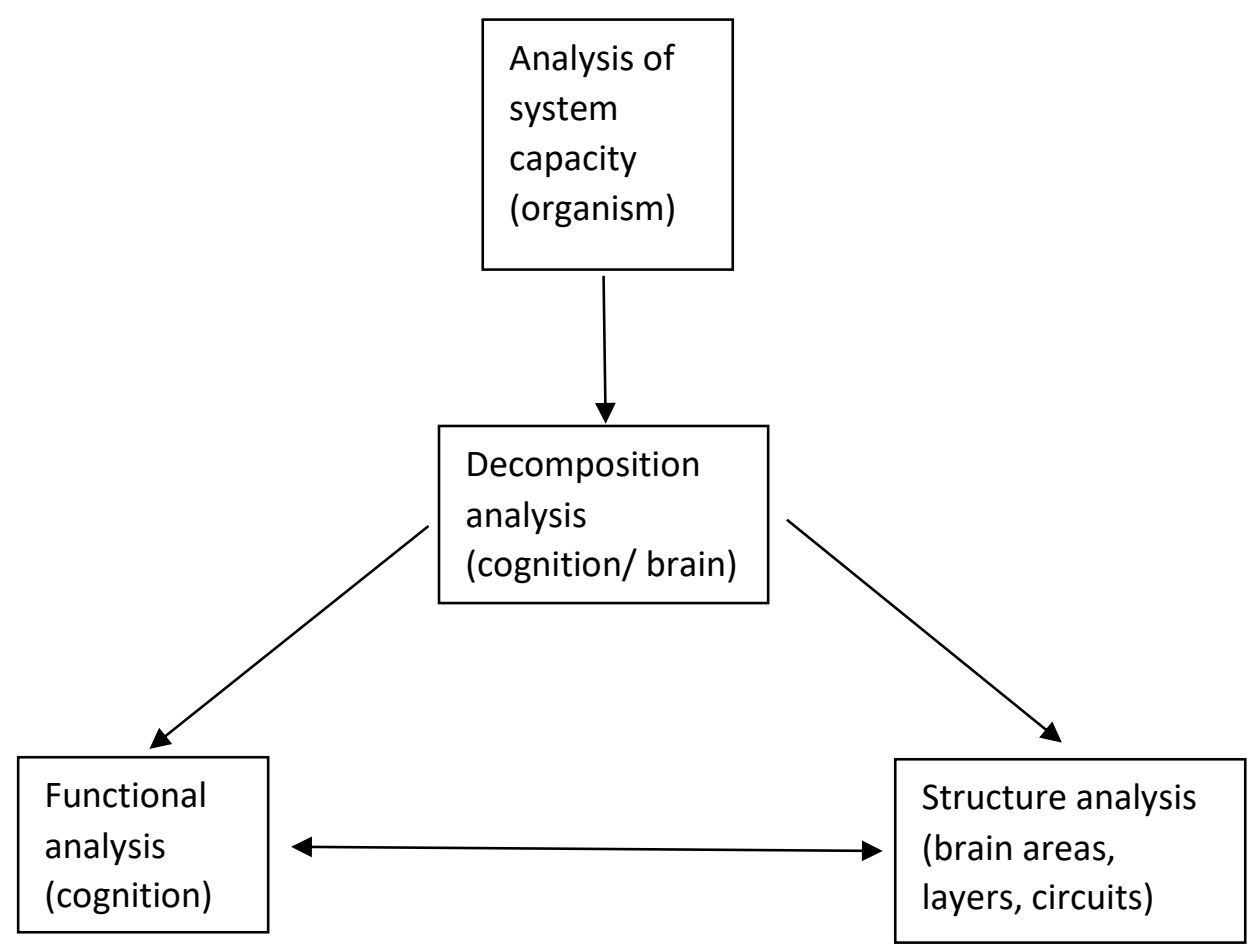

This will reveal how is the grounding of the model of the mind in neuroscience to be accomplished. 
4. Results

\subsection{Study selection}

There are 290 articles identified in searching databases of PUBMED and Google Scholar. Also, an additional record of 10 articles was identified in other sources of books. Afterwards, those identified 300 articles submitted to duplicate removal. After duplicated removal, 200 articles were identified as unique articles. Then, initial screening was done using 2 independent reviewers. From the screened articles, 85 articles were excluded, and the remaining 115 full-text articles were submitted to eligibility assessment.

Articles about cognitive science, mind models, fundamentals of neuroscience, developmental neuroscience, visual and auditory neuroscience were considered as to be eligible articles for the study. There is no year restriction, but only English language articles are considered for eligibility.

From the assessed full-text articles, 9 full-text articles were selected for synthesis. Those selected articles described cognitive architectures of mental models and neurological paths related to cognitive functions.

\subsection{Study characteristics}

Detailed interpretation of features of eligible literature is explained in Annex - Features of eligible literature.

\subsubsection{LIDA cognitive architecture}

LIDA consists of sophisticated action selection, motivation by emotions, and attention mechanism of centrally important, and multimodal instructionalist and selectionist learning. The LIDA architecture grounded a variety of modules and processes in cognitive science and cognitive neuroscience, each with its effective representations and algorithms. LIDA has explained motivation, emotion, attention, and autonomous learning in cognitive agents (Franklin et al., 2012). 


\subsubsection{Soar cognitive architecture}

Soar is also consisted of a rule-based procedural memory and includes a set of asynchronous internally parallel modules. Soar is organized around a global working memory and long-term memory (Laird, 2008). The long-term memory consists of procedural, semantic, and episodic memories.

Soar has purely symbolic representations of knowledge relied on a minimal number of architectural modules. The Soar cognitive architecture approach consists of decision procedure, reinforcement learning, chunking, semantic learning, and episodic learning.

\subsubsection{Sigma cognitive architecture}

Sigma $(\Sigma)$ cognitive architecture consists of long-term memory and working memory. Sigma long-term memory includes procedural and declarative memory. And sigma working memory includes perception and motor control (Rosenbloom and Demski, 2016).

\subsubsection{SAL cognitive architecture}

The SAL cognitive architecture is a combined model of two well-established architectures of a hybrid symbolic-subsymbolic cognitive architecture: ACT-R, and, a neural architecture: Leabra (Jilk, et al., 1983). These vastly different component architectures have a combined view of the brain, the mind, and behavior. Furthermore, both of these architectures are a single level of abstraction unable to capture the required behavioral richness. However, both architectures are internally pluralistic and recognize those models.

\subsubsection{ACT-R (Adaptive Control of Thought-Rational) Cognitive architecture}

ACT-R cognitive architecture consists of a set of independent modules that function around the central procedural module. It can describe the processes from perception through to action for a wide range of cognitive tasks. It can be used to identify models of specific tasks, which explains exact predictions in the form of response times and accuracy measures. It can address brain-wide activation patterns since ACT-R provides a model of all the components in task performance (Borst and Anderson, 2017). 


\subsubsection{EPIC cognitive architecture}

EPIC architecture explains the basic building blocks of a cognitive architecture as cognitive, perceptual, motor, and knowledge representation (Judwig, 2005). It explains the auditory processor, visual processor, ocular motor processor, visual-motor processor, manual motor processor, tactile processor as well as long-term memory, procedural memory, working memory, and production rule interpreter.

\subsubsection{Leabra cognitive architecture}

Leabra architecture tries to simulate neural activation function as a neocortical pyramidal neuron, neural learning rule as a function of neural activity, the inhibition function as inhibitory interneurons on network dynamics (Jilk et al., 1983). It explain interactions of posterior cortex (sensory representations), frontal cortex (active maintenance), hippocampus (episodic memory) and basal ganglia (action selection).

\subsubsection{Cognitive - Affective architecture}

Cognitive - Affective architecture combines affective of short term, medium-term, and long-term characteristics to the architecture (Perez et al., 2016). It includes emotions, mood, and personality. It consists of main modules of procedural memory, working memory, semantic memory, episodic memory, decision procedure, and perception module.

\subsubsection{An embodied cognitive-affective architecture}

Cognitive affective architecture embodied emotions and organisms to the cognitive architecture (Ziemke and Lowe, 2008). This explains (1) the emotional and biological mechanisms that come with the organismic embodiment of living cognitive systems, (2) models of these mechanisms can be usefully integrated with artificial cognitive systems architectures. It explains internal organization, behavioral organization, and constitutive organization. 


\subsection{Risk of bias within studies}

Articles were accessed by an individual reviewer and there are no significant differences in the article reviewed by the reviver.

\subsection{Results of individual studies}

Table 3 in the annex explains the detailed interpretation of features of the following eligible literature.

LIDA cognitive architecture

Soar cognitive architecture

Sigma cognitive architecture

SAL cognitive architecture

ACT-R (Adaptive control of thoughts - Rational) cognitive architecture EPIC cognitive architecture

\subsection{Synthesis of results}

In here synthesis across six existing cognitive architectures: LIDA, ACT-R, Sigma, Soar, Leabra, and SAL. The synthesized standard model highlights loci of architectural agreement as well as identifying potential remaining incompleteness areas. It also explains key aspects of structure and processing, memory and content, learning, and perception, and motor output processing. From those architectures, ACT-R provides a more realistic view of human psychology. Also, it explains international module, declarative module, visual module, manual module, goal buffer, retrieval buffer, visual buffer, manual buffer, a procedural module with matching, selection, and execution. It also explains the neural basis of those modules (Borst et al., 2017).

(Dancy, 2013) explains brain mapping of the ACT-R modules. It provided a more realistic view from a neural basis as well as a physiological basis. 


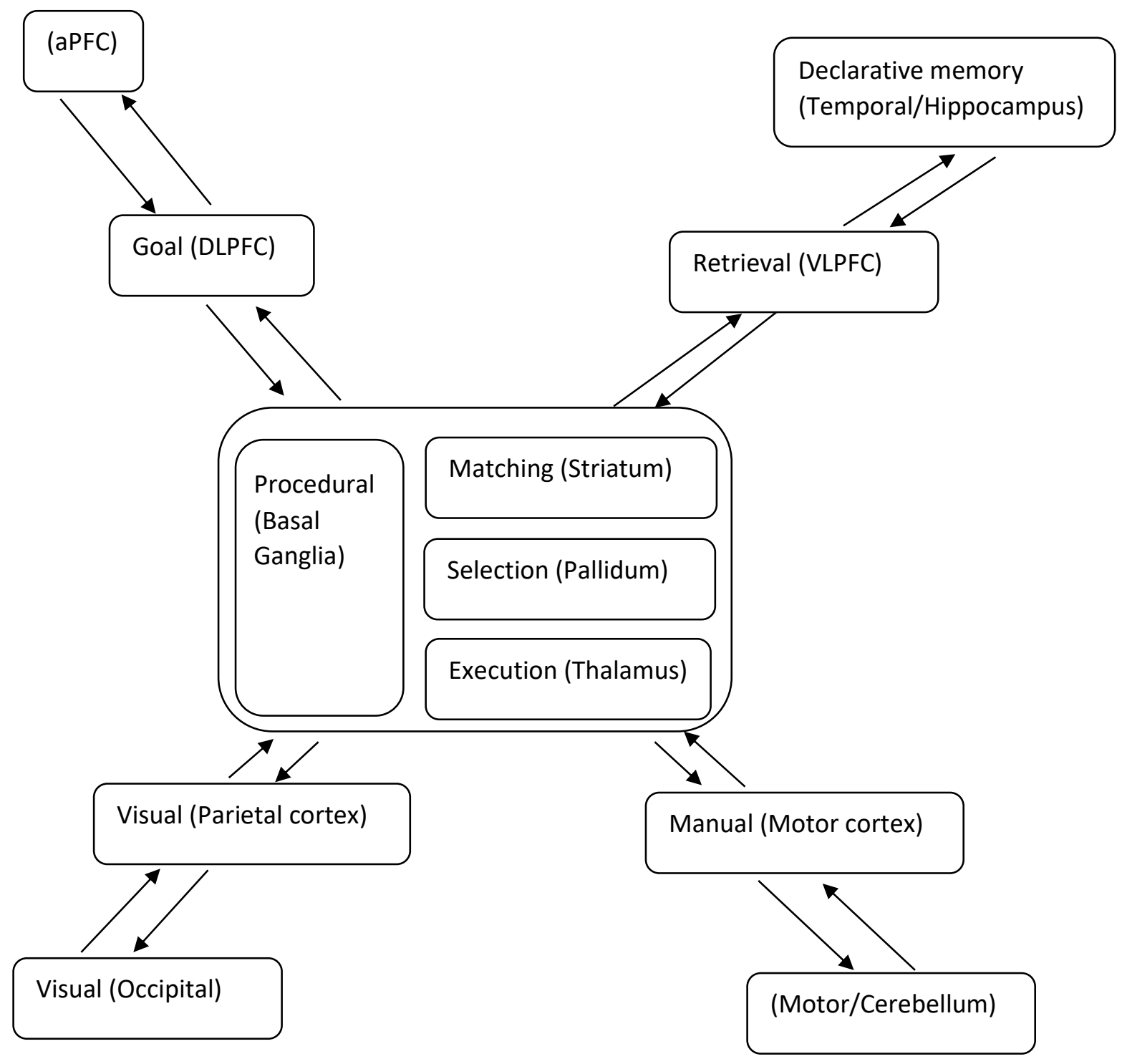

Figure 2. Mind process

Temporal/Hippocampus, VLPFC, aPFC, DLPFC, occipital, parietal cortex, cerebellum, motor cortex, basal ganglia, striatum, pallidum, and thalamus was the associative neural areas of the brain.

Lowe and Ziemke, (2015) explain the behavioral organization of the mammalian brain in cognitive-affective architecture.It also provides a more realistic view of brain organization related to the physiological view. It explains sensory inputs of cognitive analyses, context, complex natural stimuli, neutral stimuli, species-specific threat stimuli, and noxious or contact stimuli. Then, there is an explanation about those sensory inputs to brain structures 
of the frontal cortex, hippocampus \& septum, sensory cortex, thalamus, amygdala, midbrain \& hypothalamus, hindbrain, and spinal cord. Then it is explained their output to motor, autonomic and endocrine structures.

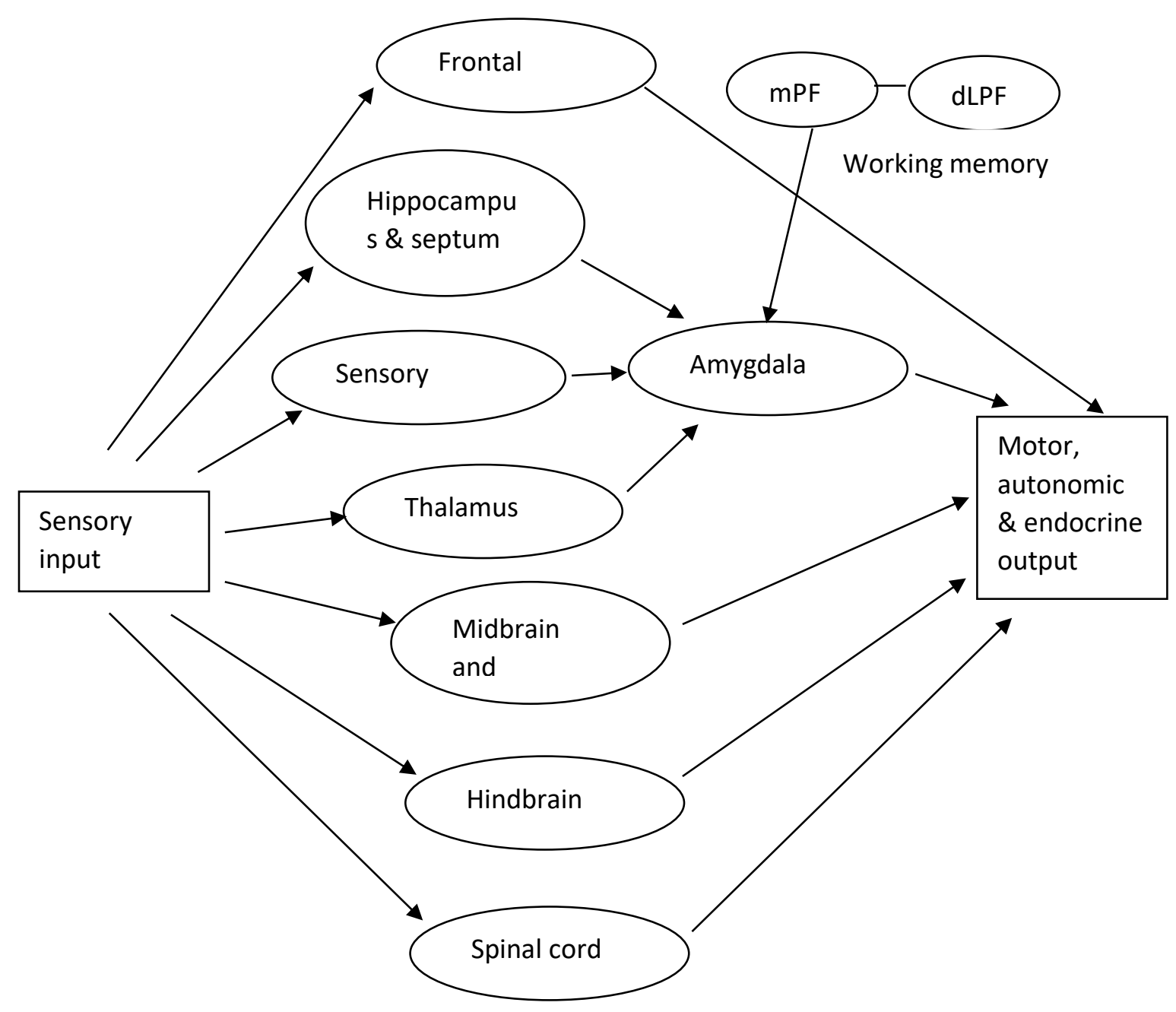

Figure 3. The architecture of mind process

Also, Lowe and Ziemke, (2015) explain interaction among the brain structures related to physiology. It explains the interaction of brain structures of the sensory cortex, hypothalamus, thalamus, amygdala, hippocampus, and working memory of mPFC and dIPFC. 
Memory is also the main brain structure in cognitive architecture. O'Reilly et al. (2012) explain the structure of the hippocampal memory system and associated temporal lobe cortical structures.

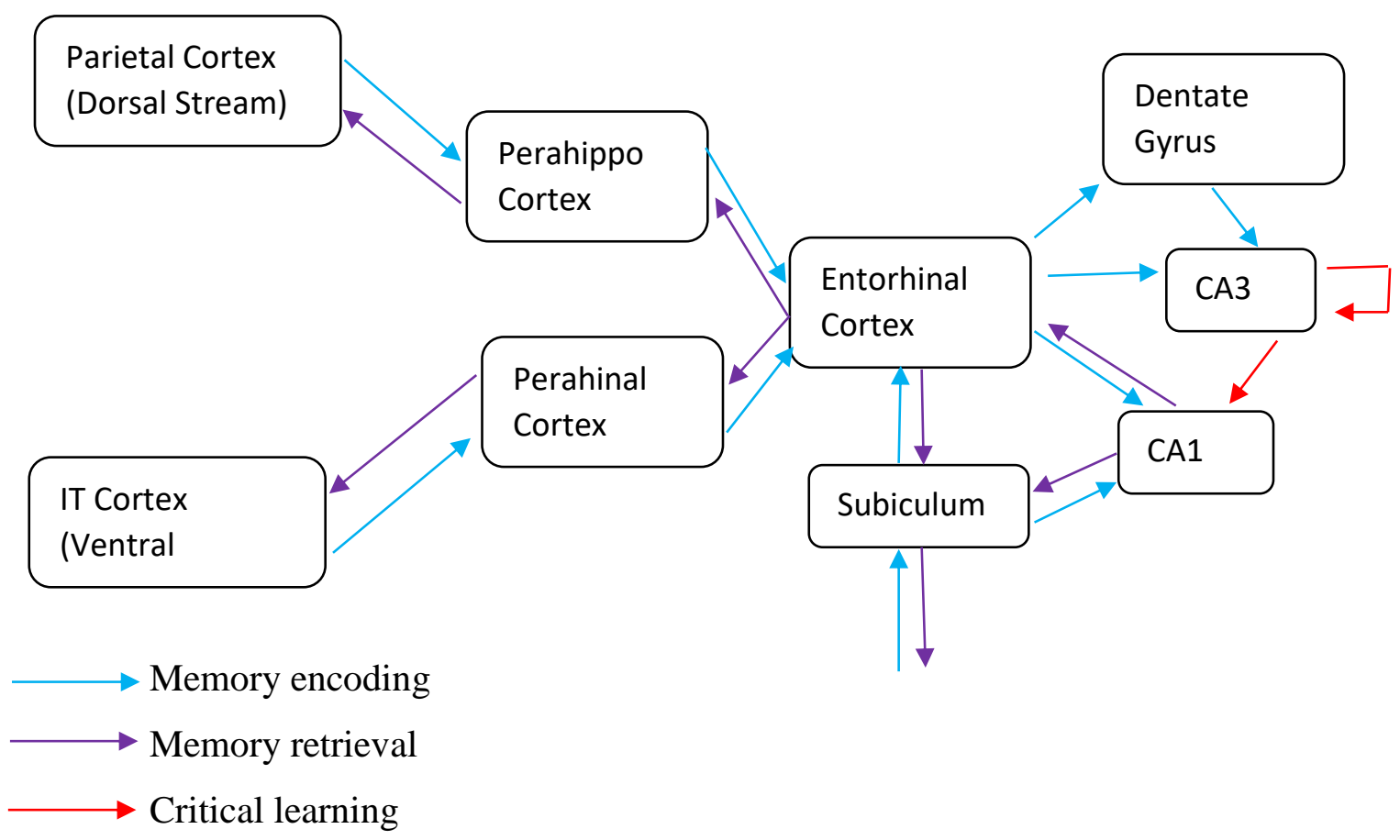

Figure 4. Process of the hippocampal memory system

It explains the memory process of memory encoding, memory retrieval, and critical learning related to brain structures of the partial cortex, IT cortex, para hippo cortex, perirhinal cortex, entorhinal cortex, subiculum, dentate gyrus, CA1 and CA3 areas of the hippocampus.

O'Reilly et al., (2012) also explains the macro architecture of the mind. Main inputs are taken from the posterior cortex. Then, active maintenance is done by the frontal cortex, episodic memory is provided by the hippocampus and the main part of the mind as action selection done by basal ganglia.

\section{6. $\quad$ Risk bias across studies}

Articles were accessed by an independent reviewer and there are no significant differences in the article reviewed by the reviver. 
5. Discussion

5.1. Summary of evidence

In this study, 9 articles were selected for further analysis and synthesis to achieve a better mental model with neurological circuit assemblies. These 9 articles include

LIDA cognitive architecture

Soar cognitive architecture

Sigma cognitive architecture

SAL cognitive architecture

ACT-R (Adaptive control of thoughts - Rational) cognitive architecture

EPIC cognitive architecture

Leabra cognitive architecture

Cognitive - affective architecture

An embodied cognitive affective architecture

Those articles describe cognitive architectures in including mind functions as well as biological assemblies of those functions.

Table 1. Summary of cognitive architectures

\begin{tabular}{|l|c|c|}
\hline Article cognitive & Mind functions & Neural assemblies \\
\hline $\begin{array}{l}\text { LIDA } \\
\text { architecture }\end{array}$ & Yes \\
\hline Soar cognitive architecture & Yes & No \\
\hline $\begin{array}{l}\text { Sigma cognitive } \\
\text { architecture }\end{array}$ & Yes & No \\
\hline SAL cognitive architecture & Yes & Yes \\
\hline
\end{tabular}




\begin{tabular}{|l|c|c|}
\hline $\begin{array}{l}\text { ACT-R(Adaptive control } \\
\text { of thoughts }- \text { Rational) } \\
\text { cognitive architecture }\end{array}$ & Yes & Yes \\
\hline EPIC cognitive architecture & Yes & No \\
\hline $\begin{array}{l}\text { Leabra cognitive } \\
\text { architecture }\end{array}$ & Yes & Yes \\
\hline $\begin{array}{l}\text { Cognitive-affective } \\
\text { architecture }\end{array}$ & Yes & No \\
\hline $\begin{array}{l}\text { An embodied cognitive- } \\
\text { affective architecture }\end{array}$ & Yes & Yes \\
\hline
\end{tabular}

From those selected architectures, considering the richness of mental functions and the richness of neurological assemblies, features of the following architectures are selected for inclusion in the final model.

ACT-R (Adaptive control of thoughts - Rational) cognitive architecture

Leabra cognitive architecture

An embodied cognitive-affective architecture

From those articles, the features included for the final model are as follows.

Table 2. Mind model abstraction from cognitive architectures

\begin{tabular}{|c|c|c|c|}
\hline Article & Mind functions & $\begin{array}{ll}\text { Detailed neural } \\
\text { circuits }\end{array}$ & $\begin{array}{ll}\text { Overall neural } \\
\text { assembly }\end{array}$ \\
\hline $\begin{array}{l}\text { ACT-R(Adaptive } \\
\text { control of thoughts - }\end{array}$ & Yes & No & Yes \\
\hline
\end{tabular}




\begin{tabular}{|l|c|c|c|}
\hline $\begin{array}{l}\text { Rational) cognitive } \\
\text { architecture }\end{array}$ & & \\
\hline $\begin{array}{l}\text { Leabra cognitive } \\
\text { architecture }\end{array}$ & No & No & Yes \\
\hline $\begin{array}{l}\text { An embodied } \\
\text { cognitive-affective } \\
\text { architecture }\end{array}$ & No & Yes & No \\
\hline
\end{tabular}

This way it was achieved the objective of the neurological circuit assembly of mind model by systematic review and synthesizing existing cognitive architectures.

\subsection{Limitations}

This study consists of a systematic review according to PRISMA guidelines for developing a mental model with neural structures assemblies. To obtain the articles, the study uses the databases of PUBMED and Google scholar. Therefore, the study is limited to available articles of those databases. Also, only English-language articles were considered. Although this systematic review was done according to PRISMA guidelines, the study uses existing articles, therefore the final model will limit to features of only available cognitive architectures. 


\section{Conclusions}

The study was done as a systematic review to find a model of a mind with neurological circuits assembled. To achieve this, the PRISMA guidelines for systematic reviews were used. The databases of PUBMED, and Google Scholar were used for literature search. Articles of 9 cognitive architectures were identified for explaining mind models.

The synthesis of cognitive architectures selects ACT-R functions as functions of the mind model. This includes an international module, declarative module, visual module, manual module, goal buffer, retrieval buffer, visual buffer, manual buffer, and a procedural module with matching, selection, and execution.

The international module is related to aPFC. The declarative module is related to the temporal/hippocampus. The visual module is related to the occipital lobe. The manual module is related to motor/cerebellum. The goal buffer is related to DLPFC. The retrieval buffer is related to VLPFC. The visual buffer is related to the parietal cortex. The manual buffer is related to the motor cortex. The procedural module is related to basal ganglia. The matching is related to the striatum. The selection is related to pallidum. Finally, the execution is related to the thalamus.

The mind takes the input of cognitive analyses, context, complex natural stimuli, neutral stimuli, species-specific threat stimuli, and noxious or contact stimuli. Then, cognitive analyses are processed by the frontal cortex; context is processed by the hippocampus and septum; complex natural stimuli are processed by the sensory cortex; neutral stimuli are processed by the thalamus; then the output of the hippocampus and septum, sensory cortex, and thalamus is processed by the amygdala; species-specific threat stimuli are processed by the midbrain and the hypothalamus; sudden distal stimuli are processed by the hindbrain and noxious or contact stimulus is processed by the spinal cord. Then, it generated output to motor, autonomic and endocrine structures.

The central structure of the mind is the amygdala. It gets sensory inputs through the sensory cortex and external stimuli through the thalamus. Process those inputs it uses working memory as $\mathrm{mPFC}$ and dLPFC. After processing amygdala provides output as behavior. 
Also, brain structures of the partial cortex, cortex, para hippo cortex, perirhinal cortex, entorhinal cortex, subiculum, dentate gyrus, CA1 and CA3 areas of the hippocampus are used for memory encoding, memory retrieval, and critical learning.

The overall posterior cortex processes the sensory and semantic inputs. The hippocampus works as episodic memory. The frontal cortex works as active maintenance of the thinking process. The basal ganglia works as action selection and the main part of the thinking process.

This reveals the mind model with neurological circuit assemblies to it. This is according to the current research done and based on this research it can enhance to find a more accurate mind model with neural structure assemblies. 


\section{Bibliography}

Borst, J.P. \& Anderson, J.R. (2017). A Step-By-Step Tutorial on using the Cognitive Architecture ACT-R in combination with fMRI Data. Journal of Mathematical Psychology 76, 94-103.

Dancy, C. L. (2013). A cognitive architecture with physiology and affect. Biologically Inspired Cognitive Architectures, 6(1), 40-45.

Franklin,S., Strain,S., Snaider, J., McCall, R.and Faghihi, U. (2012). Global Workspace Theory, its LIDA model and the underlying neuroscience. Biologically Inspired Cognitive Architectures, 1, 32-43.

Franklin, S., Madl, T., D'Mello, S., \& Snaider, J. (2014). LIDA: A Systems-level Architecture for Cognition, Emotion, and Learning. IEEE Transactions on Autonomous Mental Development, 6(1), 19-41

Gentner, D. and Stevens, A., (2014). Mental Models. Hoboken: Taylor and Francis.

Gerrans, P. and Stone,V. E. (2008). Generous or Parsimonious Cognitive Architecture? Cognitive Neuroscience and Theory of Mind. The British Journal for the Philosophy of Science. 59, 121-141

Jilk,D. J., Lebiere, C.,O'reilly, R. C. and Anderson.,J. R. (1983). SAL: An explicitly pluralistic cognitive architecture. Journal of Experimental \& Theoretical Artificial Intelligence, 20(3), 197-218.

Laird, P., (1989). mental models. In: foundations of cognitive science. Cambridge MA: MTT press, 466-499.

Laird, P. (2006). Mental Models, Sentential Reasoning, and Illusory Inferences. In C. Held, M. Knauff, \& G. Vosgerau (Eds.), Mental models and the mind: Current developments in cognitive psychology, neuroscience, and philosophy of mind, 27-51.

Laird., J. E. (2008). Extending the Soar Cognitive Architecture. Artificial General Intelligence 2008, Proceedings of the First AGI Conference, 224-235

Laird, J. E., Lebiere, C.,Rosenbloom.,P. S. (2017).A Standard Model of the Mind: Toward a Common Computational Framework Across Artificial Intelligence, Cognitive Science, Neuroscience, and Robotics. AI Magazine, 38(4), 13-26. 
Lowe, R., Ziemke, T., (2015). Towards an Enactive Cognitive Architecture. Cognitive Computation, 2009(1), 104-117.

Ludwig, J. (2005). Psychologically Inspired Symbolic Cognitive Architectures. A position paper for partial completion of the Oral Comprehensive requirement.

O'Reilly, R. C., Hazy, T. E., \& Herd, S. A. (2017). The Leabra cognitive architecture: How to play 20 principles with nature and win! The Oxford handbook of cognitive science, 91115.

Perz, J., Cerezo, E., Seron, F. J., and Rodriguez, L. F. A. (2016). Cognitive-affective architecture for ECAs, Biologically Inspired Cognitive Architectures, 18, 33-40.

Rosenbloom, P. S. and Demski, A. (2016). The Sigma Cognitive Architecture and System: Towards Functionally Elegant Grand Unification. Journal of Artificial General Intelligence, 7(1), 2017, 1-103.

Schierwagen, A. (2011). Reverse engineering for biologically inspired cognitive architectures: a critical analysis, Brain-Inspired Cognitive Systems 2010. Advances in Experimental Medicine and Biology, 718, 111-121.

Stangor, C. and Walinga, J. (2014). Introduction to Psychology - 1st Canadian Edition. Victoria, B.C.: BC campus.

Young, R., (1983). surrogates and mappings, two kinds of conceptual models for interactive devices. In: G. D and S. L.A., ed., Mental models. Lawrence Erlbaum Associates, 35-52.

Zeng, Y., Zhao, Y., Zhang, T., Zhao, D., Zhao, F. and Lu, E., (2020). A Brain-Inspired Model of Theory of Mind. Frontiers in Neurorobotics, 14(60).

Ziemke, T. and Lowe, R (2008). Towards an Enactive Cognitive Architecture. Cognitive Computation, 2009(1), 104-117. 
8. Annex - Features of eligible literature

The detailed interpretation of features of eligible literature is as follows.

\begin{tabular}{|c|c|c|c|}
\hline \multirow[t]{4}{*}{ Motivations } & LIDA, Franklin et al. (2012) & Soar, Laird (2008) & $\begin{array}{l}\text { Sigma, Rosenbloom and Demski } \\
\text { (2016) }\end{array}$ \\
\hline & $\begin{array}{l}\text { the mechanism, continual, } \\
\text { incremental } \\
\text { and online learning }\end{array}$ & Problem-solving and learning & $\begin{array}{l}\text { generic cognition, grand } \\
\text { unification, functional elegance, } \\
\text { and sufficient efficiency }\end{array}$ \\
\hline & SAL, Jilk et al. (1983) & $\begin{array}{l}\text { ACT-R, Borst and Anderson } \\
\text { (2017) }\end{array}$ & Epic, Judwig (2005) \\
\hline & $\begin{array}{l}\text { comparative anatomy, superior } \\
\text { functional capabilities through } \\
\text { tighter, principled integration }\end{array}$ & Problem solving and memory & $\begin{array}{l}\text { Multiple task performance and } \\
\text { embodied cognition }\end{array}$ \\
\hline \multirow{4}{*}{$\begin{array}{l}\text { Major } \\
\text { Assumptions }\end{array}$} & LIDA & Soar & Sigma \\
\hline & functional consciousness & $\begin{array}{l}\text { Representing cognition } \\
\text { related to problem spaces. The } \\
\text { uniformity principle. }\end{array}$ & $\begin{array}{l}\text { Reformulates an existing } \\
\text { capability to be simpler and more } \\
\text { elegant. }\end{array}$ \\
\hline & SAL & ACT-R & Epic \\
\hline & $\begin{array}{l}\text { attempt to synthesize and integrate } \\
\text { the theory of neural function, } \\
\text { network behavior, and } \\
\text { representation, theory of symbolic } \\
\text { and sub-symbolic decision-making, }\end{array}$ & $\begin{array}{l}\text { Chunks activation as } \\
\text { declarative } \\
\text { Limitation } \\
\text { processing. }\end{array}$ & $\begin{array}{l}\text { Embodied cognition. The simplest } \\
\text { assumptions make at first and } \\
\text { refined in the later stage. }\end{array}$ \\
\hline
\end{tabular}




\begin{tabular}{|c|c|c|c|}
\hline & $\begin{array}{l}\text { modular architectural } \\
\text { organization and representational } \\
\text { activation and organization }\end{array}$ & & \\
\hline \multirow{4}{*}{$\begin{array}{l}\text { Relationship } \\
\text { to } \\
\text { Neurobiology }\end{array}$} & LIDA & Soar & Sigma \\
\hline & $\begin{array}{l}\text { LIDA is a model of minds, not a } \\
\text { model of brains }\end{array}$ & $\begin{array}{l}\text { Soar does not address the } \\
\text { features of brain areas. }\end{array}$ & $\begin{array}{l}\text { Sigma does not directly address } \\
\text { features to brain areas. }\end{array}$ \\
\hline & $\overline{\mathrm{SAL}}$ & ACT-R & Epic \\
\hline & $\begin{array}{l}\text { anatomy of the basal ganglia try to } \\
\text { map the details of the production rule } \\
\text { cycle }\end{array}$ & $\begin{array}{l}\text { ACT-R tries to map the } \\
\text { particular functional areas of } \\
\text { the human brain into the } \\
\text { modules and their features of } \\
\text { ACT-R. }\end{array}$ & $\begin{array}{l}\text { Epic does not directly address } \\
\text { features to brain areas. }\end{array}$ \\
\hline \multirow[t]{3}{*}{ Modules } & LIDA & Soar & Sigma \\
\hline & $\begin{array}{l}\text { Workspace, sensory memory, } \\
\text { perceptual associative memory, } \\
\text { spatial memory, transient episodic } \\
\text { memory, declarative memory, } \\
\text { attention codelets, sensory-motor } \\
\text { memory, procedural memory }\end{array}$ & $\begin{array}{l}\text { Working memory, } \\
\text { long-term memory, perceptual } \\
\text { and motor. }\end{array}$ & $\begin{array}{l}\text { Semantic memory, episodic } \\
\text { memory, procedural memory, } \\
\text { image memory, working memory, } \\
\text { perception, and motor. }\end{array}$ \\
\hline & SAL & ACT-R & Epic \\
\hline
\end{tabular}




\begin{tabular}{|c|c|c|c|}
\hline & $\begin{array}{l}\text { declarative memory, imaginal, goal, } \\
\text { manual, vocal, aural, vision where } \\
\text { vision what }\end{array}$ & $\begin{array}{l}\text { Motor, goal, declarative } \\
\text { memory, perceptual and } \\
\text { cognitive. }\end{array}$ & $\begin{array}{l}\text { Motor, cognitive, } \\
\text { And perceptual. }\end{array}$ \\
\hline \multirow{4}{*}{$\begin{array}{l}\text { Working } \\
\text { Memory }\end{array}$} & LIDA & Soar & Sigma \\
\hline & $\begin{array}{l}\text { LIDA short-term memory consists of } \\
\text { sensory memory, conscious content } \\
\text { cue, action selection, current } \\
\text { situational model, action selection, } \\
\text { current situational model, and } \\
\text { transient episodic memory. }\end{array}$ & $\begin{array}{l}\text { Working memory capacity is } \\
\text { unlimited. It consists of } \\
\text { problem states, where states } \\
\text { are attribute or value pairs, but } \\
\text { the current state is related to } \\
\text { the duration of some working } \\
\text { memory elements. }\end{array}$ & $\begin{array}{l}\text { Sigma working memory was based } \\
\text { on working memory of object- } \\
\text { attribute value } \\
\text { triples. Working memory could be } \\
\text { changed when firing rules in long- } \\
\text { term memory. }\end{array}$ \\
\hline & SAL & ACT-R & Epic \\
\hline & $\begin{array}{l}\text { The SAL cognitive architecture is a } \\
\text { combined model of ACT-R and } \\
\text { Leabra, therefore the working } \\
\text { memory feature of ACT-R is } \\
\text { applicable for SAL as follows. } \\
\text { Working memory is both the } \\
\text { procedural as well as productions } \\
\text { memory and the contents of the } \\
\text { module buffers. There is unlimited } \\
\text { duration and capacity for declarative, }\end{array}$ & $\begin{array}{l}\text { Working memory is both the } \\
\text { procedural as well as } \\
\text { productions memory and the } \\
\text { contents of the module } \\
\text { buffers. There is unlimited } \\
\text { duration and capacity for } \\
\text { declarative, productions, and } \\
\text { the sub-symbolic aspects of } \\
\text { productions and the memory. } \\
\text { Their trieval buffer size of one }\end{array}$ & $\begin{array}{l}\text { The goals and state of production } \\
\text { rules consist in the cognitive } \\
\text { section of the general working } \\
\text { memory, along with general task } \\
\text { information. It contains unlimited } \\
\text { capacity and duration. }\end{array}$ \\
\hline
\end{tabular}




\begin{tabular}{|c|c|c|c|}
\hline & $\begin{array}{l}\text { productions, and the sub-symbolic } \\
\text { aspects of productions and the } \\
\text { memory. Their trieval buffer size of } \\
\text { one chunk is limit the number of } \\
\text { declarative objects. }\end{array}$ & $\begin{array}{l}\text { chunk is limit the number of } \\
\text { declarative objects. }\end{array}$ & \\
\hline \multirow{4}{*}{$\begin{array}{l}\text { Long Term } \\
\text { Memory }\end{array}$} & LIDA & Soar & Sigma \\
\hline & $\begin{array}{l}\text { LIDA long term memory consists of } \\
\text { perceptual associative memory, } \\
\text { special memory, declarative memory } \\
\text { (autobiographical memory and } \\
\text { semantic memory), structure building } \\
\text { codelets, attention codelets, } \\
\text { procedural memory, and sensory- } \\
\text { motor memory }\end{array}$ & $\begin{array}{l}\text { Long-term memory includes } \\
\text { production rules. Capacity is } \\
\text { unlimited. }\end{array}$ & $\begin{array}{l}\text { Long-term memory of Sigma } \\
\text { based on a parallel rule system. } \\
\text { And sigma long-term memory } \\
\text { consists of Semantic memory, } \\
\text { episodic memory, procedural } \\
\text { memory, and image memory. }\end{array}$ \\
\hline & SAL & ACT-R & Epic \\
\hline & $\begin{array}{l}\text { The SAL cognitive architecture is a } \\
\text { combined model of ACT-R and } \\
\text { Leabra, therefore the long-term } \\
\text { memory feature of ACT-R is } \\
\text { applicable for SAL as follows. SAL } \\
\text { refers to declarative memory for } \\
\text { long-term memory. Consist with }\end{array}$ & $\begin{array}{l}\text { ACT-R refers to declarative } \\
\text { memory for long-term } \\
\text { memory. Consist with items } \\
\text { called "chunks" which have } \\
\text { some number (usually less } \\
\text { than three) of weighted slots } \\
\text { and values. The number of }\end{array}$ & $\begin{array}{l}\text { The declarative } \\
\text { and working memory can be } \\
\text { stored in an unlimited number of } \\
\text { productions and propositions. }\end{array}$ \\
\hline
\end{tabular}




\begin{tabular}{|c|c|c|c|}
\hline & $\begin{array}{l}\text { items called "chunks" which have } \\
\text { some number (usually less than three) } \\
\text { of weighted slots and values. The } \\
\text { number of activation functions } \\
\text { controls the availability and recall } \\
\text { speed of chunks. These functions } \\
\text { include less-often-used activation } \\
\text { decay } \\
\text { that makes items harder to activate. }\end{array}$ & $\begin{array}{l}\text { activation functions controls } \\
\text { the availability and recall } \\
\text { speed of chunks. These } \\
\text { functions include less-often- } \\
\text { used activation decay } \\
\text { that makes items harder to } \\
\text { activate. }\end{array}$ & \\
\hline \multirow[t]{4}{*}{ Goals } & LIDA & Soar & Sigma \\
\hline & $\begin{array}{l}\text { There is no objection to options in the } \\
\text { current situational model, options are } \\
\text { converted to goals. }\end{array}$ & $\begin{array}{l}\text { The goal hierarchy called } \\
\text { universal sub-goals forms a } \\
\text { problem state. }\end{array}$ & $\begin{array}{l}\text { In the sigma model goals can be } \\
\text { achieved by searching in problem } \\
\text { spaces that are specified in terms } \\
\text { of operators and sets of states. }\end{array}$ \\
\hline & SAL & ACT-R & Epic \\
\hline & $\begin{array}{l}\text { Architectural goal stack track the } \\
\text { goals. As goals are added to } \\
\text { declarative memory as they are } \\
\text { completed. }\end{array}$ & $\begin{array}{l}\text { Architectural goal stack track } \\
\text { the goals. As goals are added } \\
\text { to declarative memory as they } \\
\text { are completed. }\end{array}$ & $\begin{array}{l}\text { In the production rules, there is a } \\
\text { goal structure and can be encoded. }\end{array}$ \\
\hline \multirow[t]{2}{*}{ Learning } & LIDA & Soar & Sigma \\
\hline & $\begin{array}{l}\text { Attentional learning is the capability } \\
\text { of LIDA-based agents. Both }\end{array}$ & $\begin{array}{l}\text { Learning, which is called } \\
\text { chunking, occurs when a }\end{array}$ & $\begin{array}{l}\text { Sigma includes long-term } \\
\text { modifications to long term }\end{array}$ \\
\hline
\end{tabular}




\begin{tabular}{|c|c|c|c|}
\hline & $\begin{array}{l}\text { instructionalist and selectionist } \\
\text { learning occur in the conscious } \\
\text { broadcast. }\end{array}$ & $\begin{array}{l}\text { resolution is found. The } \\
\text { impasse is reached if an } \\
\text { operator cannot be selected. } \\
\text { This is done using adding a } \\
\text { new production to long-term } \\
\text { memory. }\end{array}$ & $\begin{array}{l}\text { Memory was called learning. It } \\
\text { has semantic, episodic, imaginal, } \\
\text { and reinforcement learning } \\
\text { mechanisms. }\end{array}$ \\
\hline & SAL & ACT-R & Epic \\
\hline & $\begin{array}{l}\text { The SAL cognitive architecture is a } \\
\text { combined model of ACT-R and } \\
\text { Leabra, therefore the learning feature } \\
\text { of ACT-R is applicable for SAL as } \\
\text { follows. Bidirectional interface with } \\
\text { new symbol learning. Learning new } \\
\text { productions and learning new chunks } \\
\text { are included in symbolic learning. } \\
\text { Weight adjustment for chunk slots } \\
\text { and production strength adjustment } \\
\text { for production utility is the sub- } \\
\text { symbolic methods included. }\end{array}$ & $\begin{array}{l}\text { Variety of learning } \\
\text { mechanisms has in ACT-R. } \\
\text { Learning new productions and } \\
\text { learning new chunks are } \\
\text { included in symbolic learning. } \\
\text { Weight adjustment for chunk } \\
\text { slots and production strength } \\
\text { adjustment for production } \\
\text { utility is the sub-symbolic } \\
\text { methods included in ACT-R. }\end{array}$ & $\begin{array}{l}\text { Any learning capability does not } \\
\text { currently include EPIC. }\end{array}$ \\
\hline Standard & LIDA & Soar & Sigma \\
\hline $\begin{array}{l}\text { Cognitive } \\
\text { Cycle }\end{array}$ & $\begin{array}{l}\text { LIDA consist of sequences of } \\
\text { cognitive cycles. These cognitive }\end{array}$ & $\begin{array}{l}\text { 1. Input to the current state } \\
\text { from the environment }\end{array}$ & $\begin{array}{l}\text { Sigma consists of a cognitive cycle } \\
\text { with phases of input, elaboration, }\end{array}$ \\
\hline
\end{tabular}




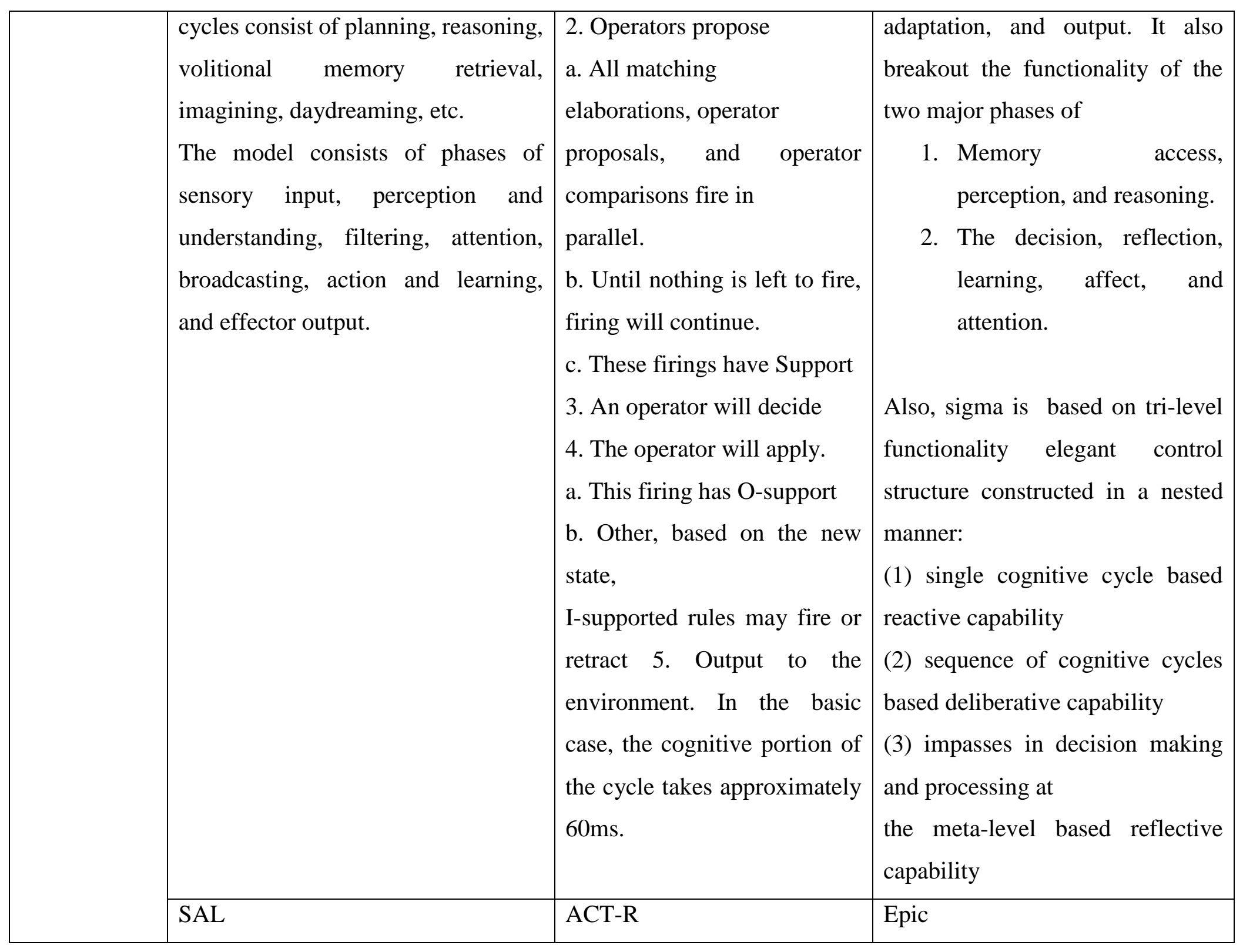




\begin{tabular}{|c|c|c|c|}
\hline & $\begin{array}{l}\text { The SAL cognitive architecture is a } \\
\text { combined model of ACT-R and } \\
\text { Leabra, therefore the standard } \\
\text { cognitive cycle feature of ACT-R is } \\
\text { applicable for SAL as follows. } 1 . \\
\text { Independent buffers that each hold } \\
\text { one chunk get input from the other } \\
\text { processors. } \\
\text { 2. With the contents of the buffers } \\
\text { combined the current goal, may } \\
\text { match several productions. } \\
3 \text {. Which production rule fires } \\
\text { determine by the production utility } \\
\text { equation. } \\
\text { 4. The production rule fires. } \\
\text { Independent buffers, Output to the } \\
\text { other processors will be generated. } \\
\text { The cognitive portion of this cycle } \\
\text { approximately takes } 50 \mathrm{~ms} \text {. }\end{array}$ & $\begin{array}{l}\text { 1. Independent buffers that } \\
\text { each hold one chunk get input } \\
\text { from the other processors. } \\
\text { 2. With the contents of the } \\
\text { buffers combined the current } \\
\text { goal, may match several } \\
\text { productions. } \\
\text { 3. Which production rule fires } \\
\text { determine by the production } \\
\text { utility equation. } \\
4 \text {. The production rule fires. } \\
5 \text {. Through the single-item } \\
\text { independent buffers, Output to } \\
\text { the other processors will be } \\
\text { generated. } \\
\text { The cognitive portion of this } \\
\text { cycle approximately takes } \\
50 \text { ms. }\end{array}$ & $\begin{array}{l}\text { 1. The working memory gets input } \\
\text { from the perceptual module. There } \\
\text { is no mechanism to convert } \\
\text { attention. } \\
\text { 2. Number of productions may } \\
\text { match the contents of working } \\
\text { memory. } \\
\text { 3. Simultaneously fire all matched } \\
\text { productions. } \\
\text { 4. Motor processor gets the output. } \\
\text { Resource conflicts are possible and } \\
\text { must be avoided by the modeler. } \\
\text { Generally takes } 50 \mathrm{~ms} \text { for the } \\
\text { cognitive portion of this cycle. }\end{array}$ \\
\hline Model & LIDA & Soar & Sigma \\
\hline
\end{tabular}




\begin{tabular}{|c|c|c|c|}
\hline Creation & $\begin{array}{l}\text { LIDA tries to model the full range of } \\
\text { activities from incoming stimuli to } \\
\text { outgoing actions. Also tries to model } \\
\text { the full range of cognitive processes } \\
\text { in between incoming stimuli and } \\
\text { outgoing actions. }\end{array}$ & $\begin{array}{l}\text { The iterative defining and } \\
\text { refining of the following } \\
\text { involves constructing a Soar } \\
\text { model: } \\
\text { 1. States representations } \\
\text { consist of } \\
\text { - Attributes with values } \\
\text { - Objects are simply values } \\
\text { with additional attributes } \\
\text { 2. Long term memory } \\
\text { productions for } \\
\text { - The initial state creation } \\
\text { - Operator proposal } \\
\text { - Evaluation of operator } \\
\text { - Application of operator } \\
\text { - Current state elaboration } \\
\text { o This includes productions } \\
\text { that check for failure or } \\
\text { desired states or that provide } \\
\text { the solution to an impasse }\end{array}$ & $\begin{array}{l}\text { Sigma was the enhancement of (1) } \\
\text { the use of problem spaces to } \\
\text { structure cognitive behavior; } \\
\text { (2) the importance of the cognitive } \\
\text { cycle two-phase structure; } \\
\text { (3) the functional elegance of a } \\
\text { nested three-layer model of control } \\
\text { that layers reactivity within } \\
\text { deliberation and } \\
\text { deliberation within reflection; } \\
\text { (4) the importance of a knowledge- } \\
\text { compilation/automatization } \\
\text { mechanism such as real-time } \\
\text { behavior chunking in the complex } \\
\text { reflective reasoning presence; } \\
\text { (5) the push for uniformity; } \\
\text { (6) approaching generic cognition } \\
\text { by modeling human cognition with } \\
\text { balancing the } \\
\text { construction of functional AI } \\
\text { systems; }\end{array}$ \\
\hline
\end{tabular}




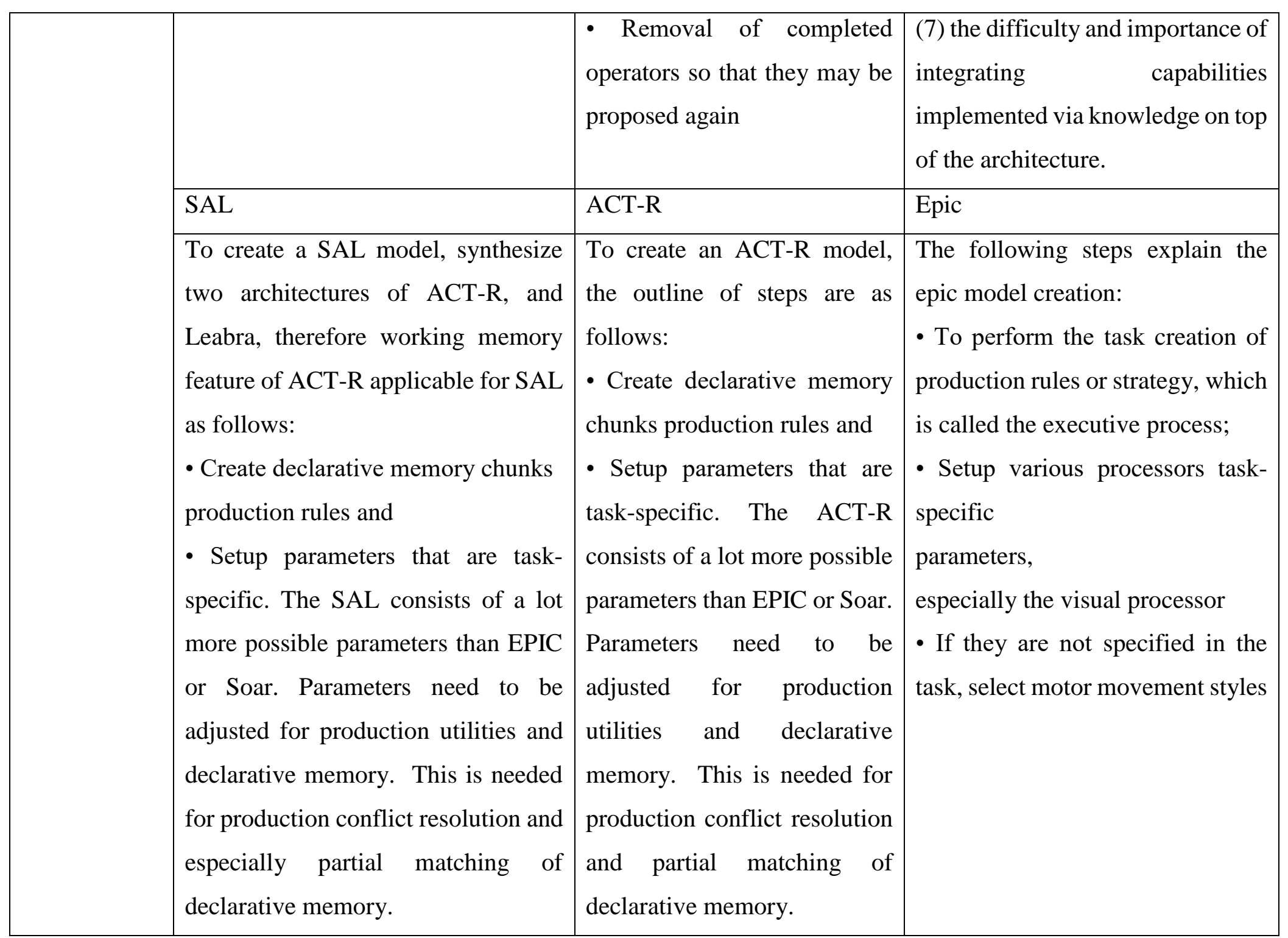

Table 3: Features of cognitive models 
